\title{
Micro void coalescence of ductile fracture in mild steel during tensile straining
}

\author{
P. K. Pradhan, P. R. Dash \\ Mechanical Engineering, VSS University of Technology, Burla, Odisha, India \\ prasant2_pradhan@yahoo.com
}

P. S. Robi

Mechanical Engineering, IIT, Guwahati, India.

Sankar K. Roy

Mechanical Engineering, IIT Kharagpur

\begin{abstract}
The ductile fracture occurs mainly in three stages i.e. void nucleation, void growth and the void coalescence. The present work focuses on the study the coalescence of existing micro void in a ductile material, mild steel. The specimen with holes in square array at various angle to load axis have been tested. The holes were machined in the specimen and assuming those hole as the voids. The growth and coalescence behaviours during tensile straining were observed both in macro and micro levels. Since the existing facility is not adequate to make hole size in micron, this work has been carried out by making hole upto 500 micron. The results are compared with other specimen with bigger size hole and without any hole. Also the effects of micro voids (present in the material) on the progress of crack have been studied. It is found that with same amount of voids, present in different positions, the mechanical properties of the material are altered.
\end{abstract}

KEYWORDS. Ductile fracture; Micro void; Coalescence; Crack propagation; Microstructure.

\section{INTRODUCTION}

$\mathrm{F}$ racture of structural components has been a common phenomenon faced by men for as long as structures have been used. Griffith [1] identified that surface energy, i.e. the amount of energy is required for a crack to grow. This theory in the original form is applicable only to a perfectly brittle material such as glass. Later Irwin and Orwan [2] modified this for the ductile material considering the energy required for plastic deformation at the crack tip. Fracture may be classified into two groups: One is brittle fracture and the other one is ductile fracture. Brittle fracture occurs suddenly and with no or very less deformation. Ductile fracture is always associated with large amount of plastic deformation and it consists mainly of three stages, (i) void nucleation, (ii) void growth and (iii) void coalescence.

Nucleation of voids in materials occurs generally at second phase particles or at inclusions. Goods and Brown [3] developed a dislocation-based model of void nucleation. According to them, when the total stress (summation of local stress, flow stress and hydrostatic stress) exceeds the interfacial bond strength, the voids nucleate. Further increase in the external remote stress result in the continuous volumetric growth of voids. Rice and Tracey [4] found that the micro void undergoes a volumetric growth and shape change due to the continued plastic flow of matrix. Bandstra [5] has done some experiments with simulation and found that growth rate accelerates with the strain rate with the transverse orientations 
towards the neighbouring voids in the manner that depends on strain hardening coefficient (n). Later, Taktak et al. [6] have proposed a modification of Rice and Tracey model by introducing corrective co-efficient.

Coalescence of voids occurs followed by gradually and continuous volumetric growth and shape change of the voids under stress-strain field. This coalescence of voids leads to final fracture. Thomason [7] has given the limit load condition required to initiate internal necking of intervoid matrix. Rui et al. [8] studied the fracture of FeNi42 alloy and observed that coalescence of micro voids occurs only in localized necked regions. When the space of adjacent micro voids is smaller, they coalesced directly and when the space is bigger, these are usually linked by several smaller voids nucleated presumably by fine carbides or very small inclusions. Tvergaard [9] has done a model analysis of void growth and coalescence and found that for a very small void volume fraction the crack-tip tends to interact with one void at a time, while larger void volume fractions lead to simultaneous interaction of multiple voids on the plane ahead of the crack-tip.

Gao and Jinkook [10] obtained the failure criterion for a material is a function of the stress triaxiality parameter and the load angle. Zhang and Skallerud [11] found that effect of pre-strain induced void shape change on coalescence strain is relatively small while the effect of pre-strain induced local hardening is significant. In a study, Milza at al. [12] got that void nucleation and coalescence both have a very strong dependence on stress tri-axiality, but appear to be less sensitive to strain-rate for ductile material like pure copper. Osman [13] observed that due to presence of free graphite and nonspheroidal graphite in ductile cast iron, the fatigue crack initiate and propagates easily and the fatigue strength decreases.

Fracture of materials depends upon many parameters like the state of stress, strain rate, the defect size, crystal structure, chemical homogeneity, grain size, grain boundary, formation of twins and slip plane, temperature and environmental conditions. In an experimental study, Nath and Das [14] found that fine grained structure have higher value of fracture toughness than a coarse grained structure for medium carbon steel.

Many scientists have proposed many theories both in microscopic and macroscopic levels. Various theories exist, that explain the mechanisms of void nucleation, growth and coalescence. However, only a limited number of experiments have been carried out to validate these theories. Keeping in view of these facts, the present work attempts to study the coalescence of existing micro void in a ductile material, mild steel. Micro sized holes were machined on flat specimen and their growth and coalescence behaviour were observed. The results obtained from the experiments are discussed assuming that machined holes are acting as voids in ductile material. Since the mild steel is widely used engineering material and is ductile in nature, it is taken for this experimental work.

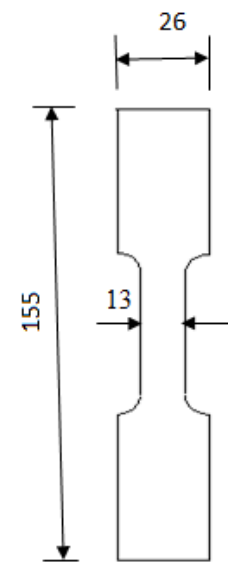

(a)

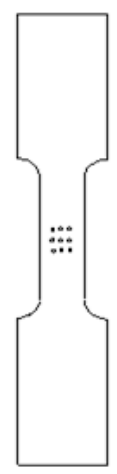

(b)

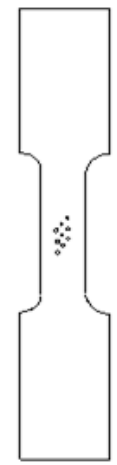

(c)

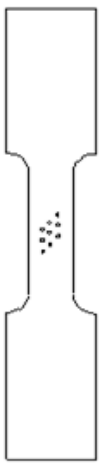

(d)

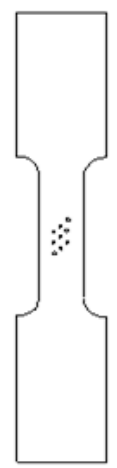

(e)

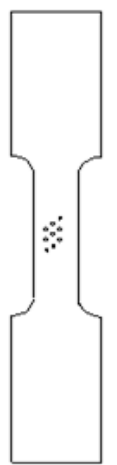

(f)

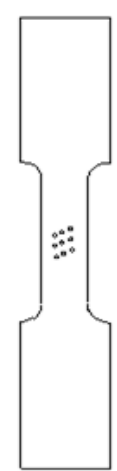

(g)

Figure 1: Rectangular specimen with arrays of holes at different orientations: (a) Specimen without hole, (b) hole array at $0^{0} / 90^{\circ}$, (c) at $30^{\circ}$, (d) at $40^{\circ}$, (e) at $45^{\circ}$, (f) at $50^{\circ}$ and (g) at $60^{\circ}$.

\section{EXPERIMENTATION}

Plan of Experiment

T 7 ith reference to the aforesaid objective, the experimental work has been planned in the following sequence.

I. Preparation of flat rectangular specimen of thickness $1 \mathrm{~mm}$. (as shown in Fig.1(a)) made of mild steel.

II. In some specimen arrays of hole (of size $1 \mathrm{~mm}$ diameter) were made and some specimen were kept as 
plain (i.e.without any hole).

III. Tensile deformation of rectangular plain specimen (without any hole).

IV. Tensile deformation of rectangular specimen containing arrays of holes.

V. Microstructural study of the above deformed specimen under Optical Microscope and Scanning Electron Microscope (SEM).

VI. Preparation of flat square specimen of thickness $1 \mathrm{~mm}$. (as shown in Fig.2).

VII. Arrays of hole (of size $0.5 \mathrm{~mm}$. diameter) have been made in such square specimen.

VIII. Tensile deformation of those specimen under Optical Microscope.

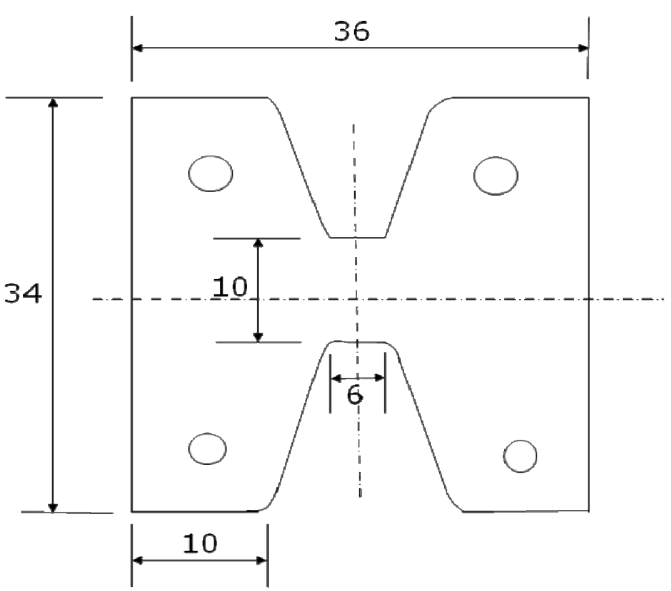

Figure 2: Flat square specimen (thickness $1 \mathrm{~mm}$.)

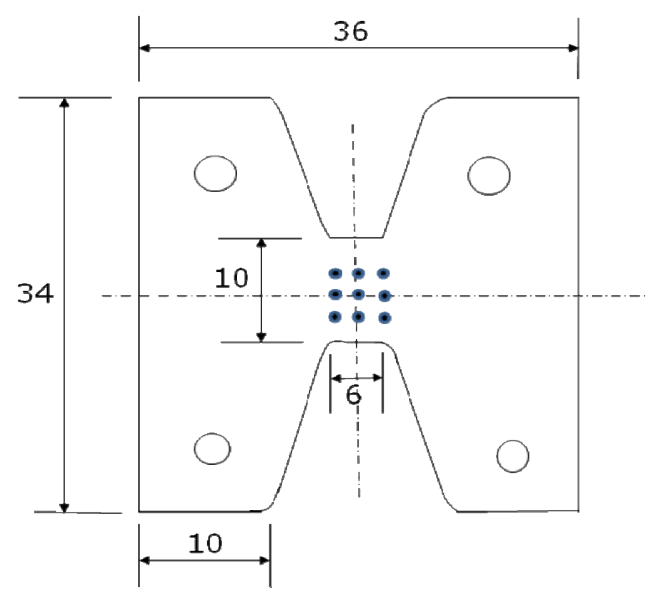

Figure 3: Square specimen with array of hole.

\section{Preparation of Specimen}

Fifteen numbers of rectangular specimen of thickness $1 \mathrm{~mm}$ were prepared from mild steel using surface grinding machine. Utmost care was taken to avoid overheating and undue deformation. Out of fifteen specimen, in six specimen $(3 \times 3)$ arrays of hole were made with different angle of inclination, i.e. 00, $300,400,450,500$ and 600 to the tensile load axis (as shown in Fig.1(b)-(g)) using drilling machine. The size of each hole was $1 \mathrm{~mm}$. In similar way, the square specimen of thickness $1 \mathrm{~mm}$. containing arrays of hole (of size $0.5 \mathrm{~mm}$. diameter) with different inclination (as shown in Fig.3) were prepared. The $0.5 \mathrm{~mm}$. holes were made by laser drilling machine and used for void coalescence studies (during straining) directly under optical microscope. These specimens were electro polished before testing to obtain a metalographically polished samples. Square specimen, except rectangular specimen have been taken for this test because these were tested under optical microscope directly and the attachment for this test does not permit other than this size.

\section{Experimental Procedure}

This experimental work mainly consists of:

I. Tensile deformation of rectangular specimen without any holes;

II. Tensile deformation of rectangular specimen containing $1 \mathrm{~mm}$ diameter holes;

III. Tensile deformation of square specimen containing $0.5 \mathrm{~mm}$ diameter holes;

IV. Microstructural studies of the above specimen.

Tensile deformation of flat rectangular specimen without any boles

Tensile deformation of all the rectangular specimens without any holes were carried out in a Universal Testing Machine (UTM, Make: INSTRON, Model: 8803, shown in Fig.4). Tensile tests were carried out with a crosshead speed of 2 $\mathrm{mm} / \mathrm{min}$. First, one specimen is tested till failure to get the mechanical properties of the material like Young's modulus (E), yield point etc. Then another specimen is tested by repeated loading and unloading at different plastic strain to get the change of $\mathrm{E}$ for corresponding strain.

Seven numbers of independent specimens were also loaded upto $8,12,16,20,25,30$, and $40 \%$ plastic strains and the tests were interrupted. These specimens were used to study the effect of strain on the void density by micro-structural observation using an optical microscope, SEM and Zeiss software. The observed void density (or void volume fraction) was measured by taking average of twenty subsequent adjacent area of the specimen and that is compared with actual void density. Actual void density is calculated relative to material density. The material density was determined by Density Kits. Also corresponding changes of grain size have been studied. 


\section{Tensile deformation of flat rectangular specimen containing $1 \mathrm{~mm}$ diameter holes}

These sets of experiments were carried out using the specimen geometry as shown in Fig.1. The specimens were loaded in the UTM with crosshead speed of $2 \mathrm{~mm} / \mathrm{min}$. On-line observation of the shape change of holes during tensile loading were taken by using a charge coupled device (CCD) camera interfaced to the computer. An objective lens having a magnification of $10 \mathrm{X}$ was attached to the CCD camera. The images transmitted to the computer were captured using Zeiss KS-300 software. The camera stage had provision of shifting the camera along all the three co-ordinate axis. Fig.5 shows the platform used for this purpose.

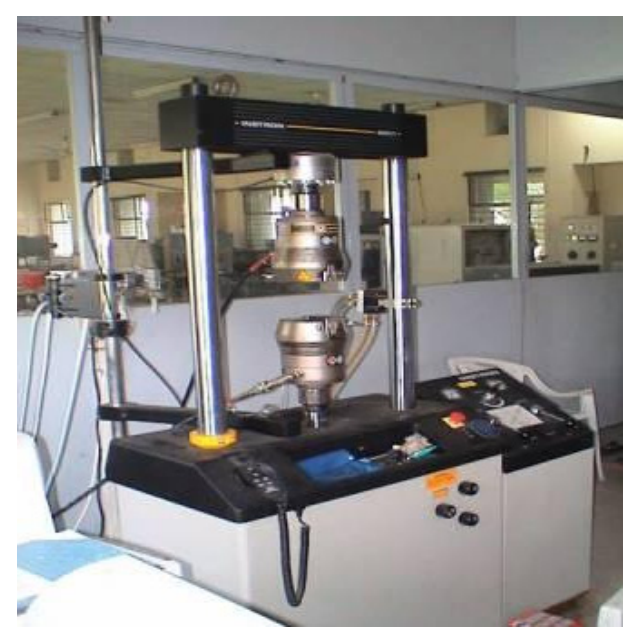

Figure 4: UTM (INSTRON) Machine.

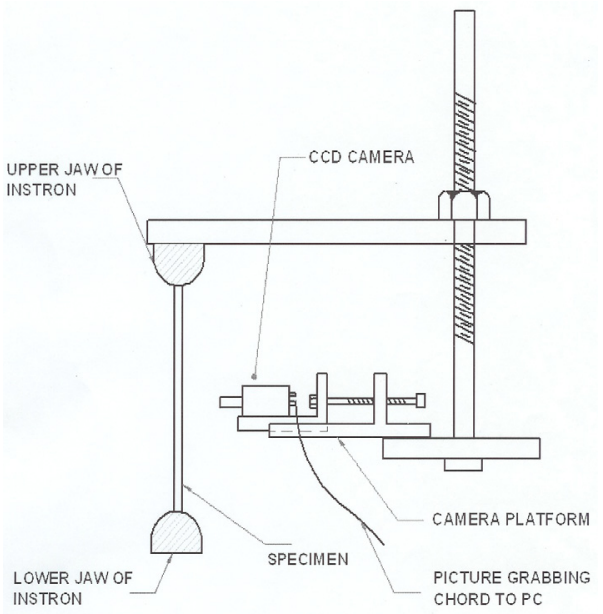

Figure 5: CCD camera stage

\section{Tensile deformation of flat square specimen containing $0.5 \mathrm{~mm}$ diameter boles}

Tensile deformation studies of specimen containing $0.5 \mathrm{~mm}$ holes were carried out using the specimen shown in Fig. 3. These tests were carried out in a tensile stage, which was an attachment to the electron microscope (Make: Deben, Model: Microtest 5000). The tensile stage was kept below the optical microscope and loaded in tension. The various observations were made using the microscope and recorded by the Zeiss KS-300 Image analysis software. All these test were carried out with a crosshead speed of $0.02 \mathrm{~mm} / \mathrm{min}$ till failure.

\section{Microstructural studies}

Deformed samples were polished by using the standard specimen preparation method for microstructural observation. The samples were obtained by taking section around maximum deformed or cracked region and these pieces were reduced to half of thickness by surface grinding. The machined surface is mounted in thermosetting resin and then polished using 220, 400, and 600 grit emery papers. This was followed by fine polishing using $1 \mu \mathrm{m}$ diamond paste on a lapping cloth and subsequently on alumina suspension solution. The fine polished samples were etched using 3\% Nital solution for revealing the microstructure under the optical microscope. Micro structural observations were made on the undeformed samples as well as deformed samples strained to various degrees. The crack tip in the cases of samples containing holes was also observed in the similar way to study the exact path of the crack propagation. For this, the specimen were sectioned around the crack tip after the test followed by thinning to half the thickness using a surface grinder before mounting on the thermo-plastic resin. Some studies have been carried out under Optical Microscope and some others under SEM. For study under SEM, etching is not required. Microstructural studies of square specimen have done directly under electron microscope during straining.

\section{RESULTS AND DISCUSSION}

he results of tensile tests and microstructural investigations are presented and discussed in the following to give better understanding of the effects of microvoids and their coalescences.

Tensile behaviour of specimen without holes

The yield strength $\left(\sigma_{\mathrm{yp}}\right)$, Young's modulus $(\mathrm{E})$, fracture stress $\left(\sigma_{\mathrm{f}}\right)$, UTS and strain at UTS of the specimen material (mild steel) are $244 \mathrm{MPa}, 203.9 \mathrm{GPa}, 263.5 \mathrm{MPa}, 366.4 \mathrm{MPa}$ and 22.3\% respectively. The plot obtained during the repeatedly 
loading and unloading cycles of the tensile test is shown in Fig. 6. The variation of Young's modulus (E) value due to the plastic deformation, during tensile loading after each unloading operation, is plotted in Fig. 7. It is evident that the value of E decreases with increase in strain (\%). The decrease in E's value with increase in strain may be due to the nucleation of voids in the matrix during the tensile deformation. In each successive deformation, the newer voids nucleate and earlier nucleated voids grow. Due to that, the void's volume fraction in the material increases. Therefore, for the same amount of strain, lesser force required and the value of E decreases.

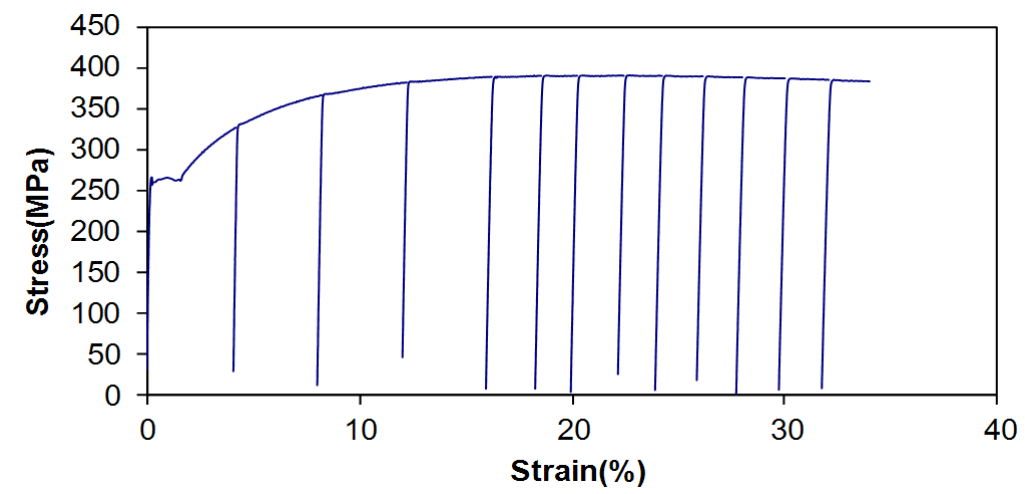

Figure 6: Stress-strain curve obtained during the loading and unloading operation for the flat tensile specimen.

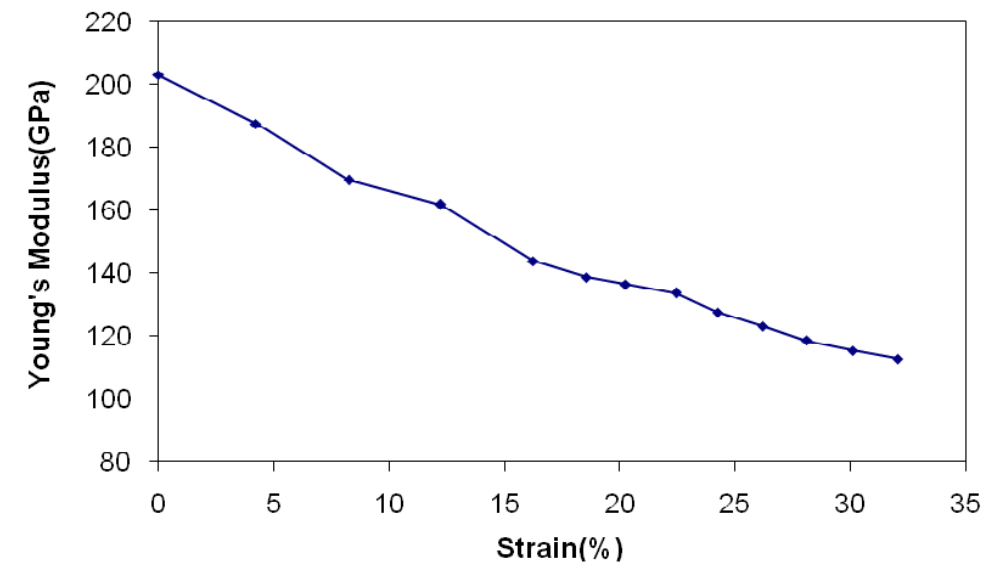

Figure 7: Change of E (Young's modulus) for corresponding strain (\%)

\section{Microstructural study of specimen without boles}

Microscopic observation of the polished and etched undeformed specimen revealed the structure consisting of ferrite grains with small amount of pearlite colonies (black regions shown in Fig. 8) at the ferrite grain boundaries. The image analysis results revealed $13.10 \%$ of pearlite indicating a carbon percentage of $0.15 \%$ for the steel.

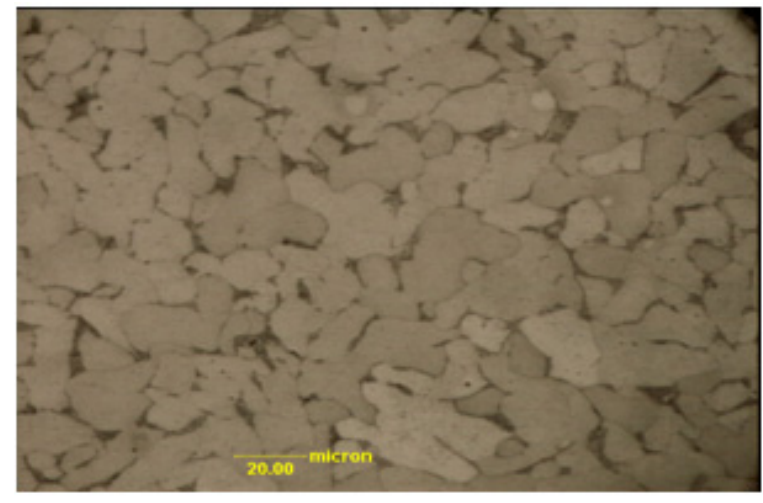

Figure 8: Structure of undeformed specimen.

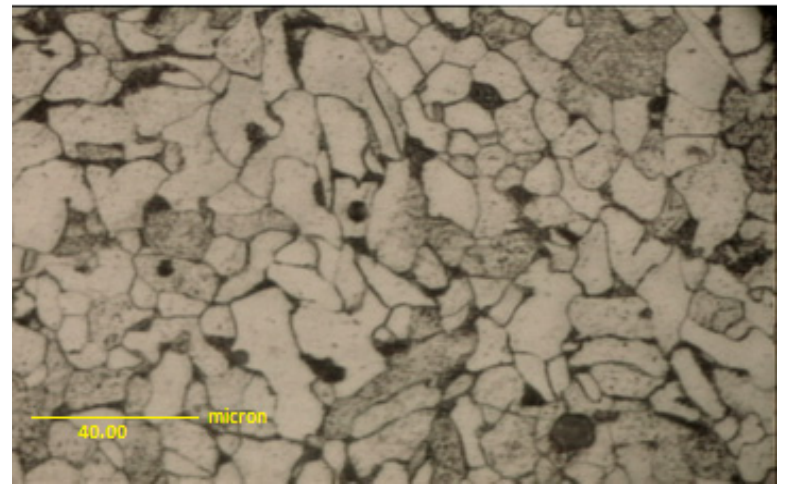

Figure 9: Void nucleation at grain boundary. 
It was not possible to precisely locate the exact position of void nucleation site using the optical microscope. Fig 9 shows the microphotograph of etched specimen strained at $12 \%$. Voids are nucleated at the grain boundaries rich in pearlite as evident by the dark regions at the grain boundaries. In the present investigation, the elongation of the grains along with void formation at the grain boundaries is observed in Fig. 10 (a) and (b). It is clear that individual ferrite grains elongate parallel to the load axis during the tensile deformation. This is also evident from the stretch factor (SF) values of the image analysis results shown in Tab. 1. Ashby and Verrall [15] had proposed a mechanism of deformation in poly crystalline material in which the poly crystals were assumed to deform by disassembling in to constituent grains and then deforming. The deformation consists simultaneous action of grain elongation and rotation. During this process, overlapping of individual grains as well as void formation at the grain boundaries occurs which are subsequently taken care of statistically stored dislocations and geometrically necessary dislocations.

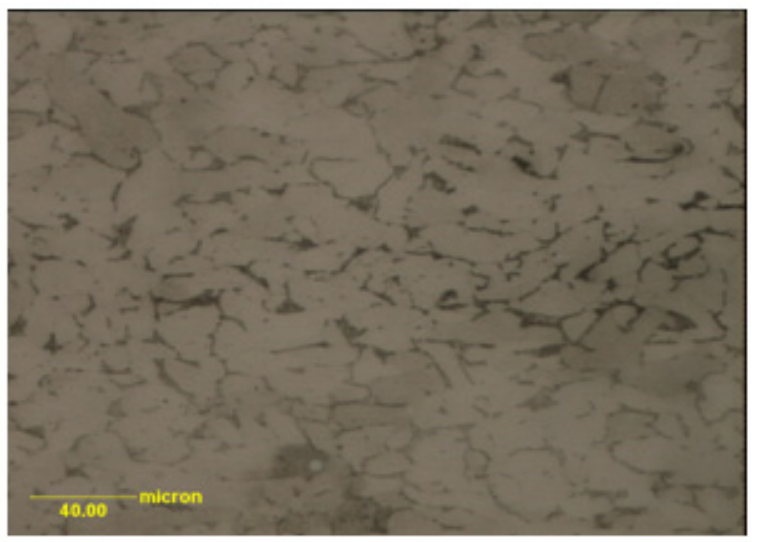

(a)

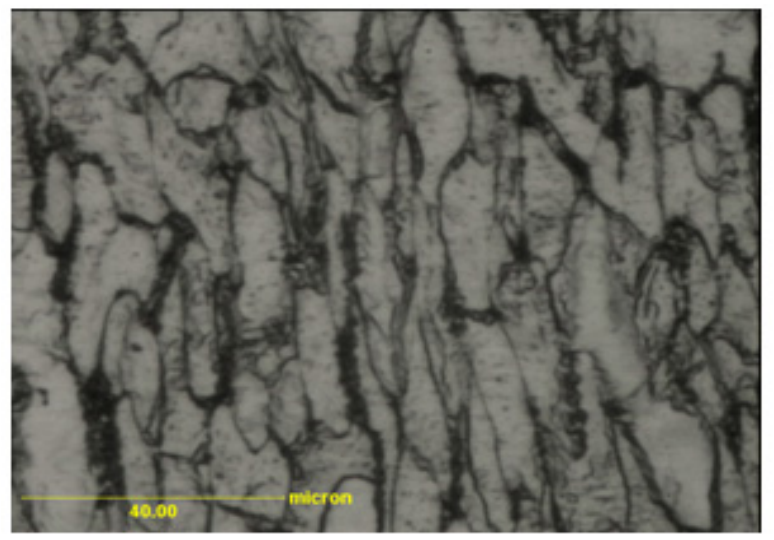

(b)

Figure 10: Elongated grain at (a) 20\% strain and (b) $40 \%$ strain. (The tensile load axis is horizontal and vertical respectively for the above figures).

\begin{tabular}{|c|c|c|c|c|c|c|c|}
\hline Sl. No. & Strain $(\%)$ & $\begin{array}{c}\text { Grain Size } \\
\text { (A)ASTM } \\
\text { No. }\end{array}$ & $\begin{array}{l}\text { Stretch } \\
\text { factor }\end{array}$ & $\begin{array}{c}\text { Density after } \\
\text { deformation } \\
\left(\mathrm{Kg} / \mathrm{m}^{3}\right)\end{array}$ & $\begin{array}{l}\text { \% reduction } \\
\text { in E's value }\end{array}$ & $\begin{array}{l}\text { Actual Void } \\
\text { volume } \\
\text { fraction }(\%)\end{array}$ & $\begin{array}{l}\text { Observed } \\
\text { void volume } \\
\text { fraction }(\%)\end{array}$ \\
\hline 1 & 0 & 8.15 & 0.82 & 7883.4 & --- & 0.12 & 0.12 \\
\hline 2 & 4 & 8.11 & 0.84 & 7863.57 & 9.237 & 0.371 & 0.25 \\
\hline 3 & 8 & 8.16 & 0.85 & 7843.26 & 13.79 & 0.625 & 0.26 \\
\hline 4 & 12 & 8.17 & 0.88 & 7820.4 & 19.10 & 0.910 & 0.54 \\
\hline 5 & 16 & 8.13 & 0.91 & 7795.6 & 20.65 & 1.232 & 0.83 \\
\hline 6 & 25 & 8.15 & 0.94 & 7762.25 & 22.02 & 1.6549 & 1.67 \\
\hline 7 & 30 & 8.12 & 0.95 & 7762.0 & 24.81 & 1.66 & 1.214 \\
\hline 8 & $\begin{array}{c}40 \\
\text { (Fracture) }\end{array}$ & 8.11 & 0.96 & 7723.5 & ---- & ---- & ----- \\
\hline
\end{tabular}

Table 1: Structural changes of specimen for various strains (\%).

Tab. 2 shows that when strain (\%) increases, the stretch factor increases. It indicates that the grains are elongated due to deformation of the specimen. But the effect of strain (\%) on grain size (ASTM No.) is not significant in this test. The density of the steel, percentage decrease in the E's value, the observed void volume fraction (from the Image analysis data) and actual void volume fraction calculated as per the rule of mixtures (from the density data) for the steel, obtained from individual specimen after straining to the specified values are shown. It is observed from Tab. 2 that with increase of 
strain (\%) density of the material decreases due to increase of void density. It indicates that void nucleation and void growth is a continuous process during tensile deformation.

\section{Tensile Behavior of rectangular specimen with holes}

The tensile deformation behavior of the steel specimens containing holes were similar to that of the specimen without holes. However, the yield point (Y.P) and the Young's modulus (E) of the material decreases due to the presence of holes. Mechanical Properties obtained from these tests are given in Tab. 2.

\begin{tabular}{ccccccc}
\hline Sl.No. & $\begin{array}{c}\text { Hole array } \\
\text { inclination angle } \\
\text { (degree) }\end{array}$ & $\begin{array}{c}\text { UTS } \\
(\mathrm{MPa})\end{array}$ & $\begin{array}{c}\text { Strain at } \\
\text { UTS }(\%)\end{array}$ & $\begin{array}{c}\text { Young's } \\
\text { Modulus E, } \\
(\mathrm{GPa})\end{array}$ & $\begin{array}{c}\text { Yield point } \\
(\mathrm{MPa})\end{array}$ & $\begin{array}{c}\text { Fracture } \\
\text { Strain }(\%)\end{array}$ \\
\hline 1 & Without hole & 366.07 & 22.3 & 203.9 & 244.5 & 42.4 \\
2 & $0^{0}\left(\right.$ or $\left.90^{\circ}\right)$ & 232.4 & 11.5 & 145.6 & 174.7 & 17.4 \\
3 & $30^{\circ}$ & 234.9 & 12.3 & 149.5 & 182.6 & 22.9 \\
4 & $40^{0}$ & 238.9 & 13.8 & 154.8 & 184.5 & 23.8 \\
5 & $45^{0}$ & 244.8 & 15.0 & 165.4 & 188.2 & 25.1 \\
6 & $50^{0}$ & 238.0 & 12.9 & 153.2 & 186.0 & 23.1 \\
7 & $60^{\circ}$ & 239.5 & 12.1 & 148.3 & 179.7 & 22.8 \\
\hline
\end{tabular}

Table 2: Mechanical properties of rectangular specimen with hole.

During deformation, the average width of the specimen is reduced. Due to stress concentration, the region adjacent to holes along the plane at mid section of the major axis showed large deformation. Shear band formation parallel to the array direction and passing through the holes is also observed (Fig. 11). The significant observations are obtained from the test results are:

I. Mechanical properties of the specimen with holes decreases compared to specimen without holes.

II. Among specimen with hole, with increase of angle of orientation to the tensile axis, the yield point, UTS, E, strain at UTS and fracture strain increases up to $45^{\circ}$ and then decreases.

III. For the specimens with hole array inclined at $90^{\circ}$ (same as $0^{\circ}$ ) to the specimen edge, the fracture strain was least. Shear band formation is not observed in this sample.

IV. Yield point phenomena is not found in specimen without hole.
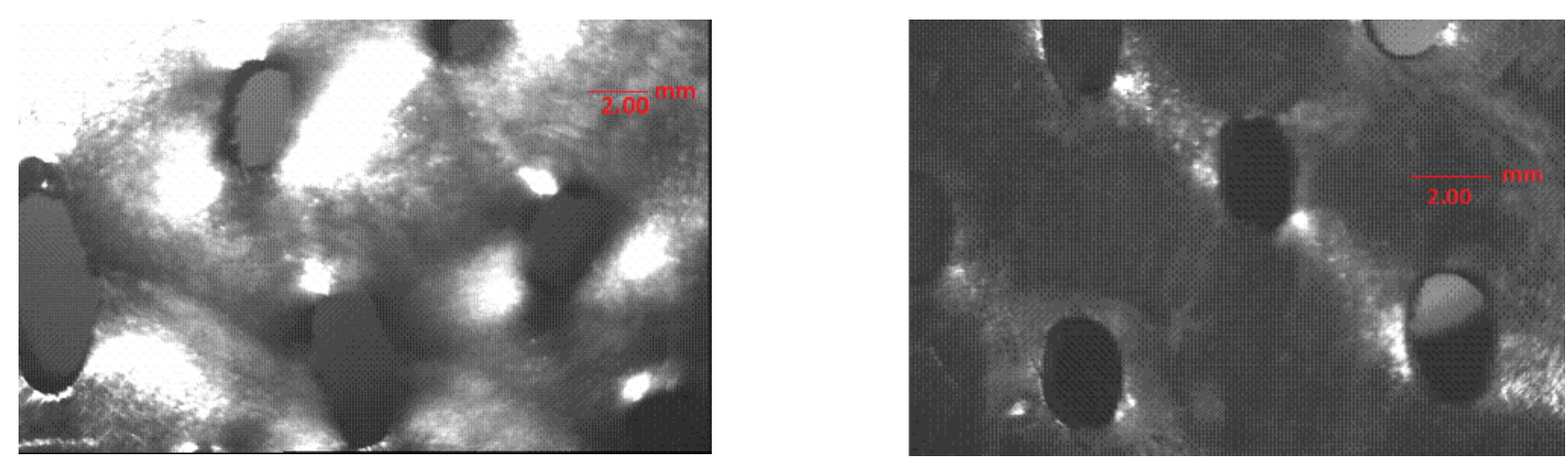

Figure 11: Shear band formation during the tensile deformation of specimen (For Hole orientation (i) $60^{\circ}$ and strain at $16 \%$, (ii) $45^{\circ}$ and strain at $18 \%$ respectively).

\section{Macroscopic observation of the deformation of holes and fracture path}

From the observation (through the CCD camera) of the specimens with regular hole arrays during tensile testing, it was revealed that continuous deformation of holes takes place along the principal strain axis. Further, the major diameter of the holes increased continuously till the maximum load is reached. After the maximum load is reached, tensile instability occurs due to unstable deformation along localized region. On a macroscopic level, it appears that the failure process in these specimens is by shearing along the plane of intense shear band formation. The fractured path is found to be passing 
through the machined holes. The material in between the holes have deform substantially. This leads to the shear band formation connecting the machined holes along an easy path, resulting in the final fracture. However, it is observed that the crack propagation is not exactly along the middle of the shear band (i.e. not along the shortest path between the holes).

\section{Microscopic study of fracture path}

In order to identify the exact crack path and the mechanism of failure of the material containing the machined holes, the specimens were not allowed to fail completely. The region ahead of the growing crack was sectioned, and thinned by the surface grinder. These were mounted in thermosetting resin, polished, etched and then observed under the microscope to investigate the exact crack path. The microphotograph of one such sample is shown in Fig. 12. In microscopic level, propagation of crack is not truly linear, it is zig-zag. As discussed by Stec and Faleskog [16], due to differences in orientation of cleavage planes of two neighbouring grains, crack changes its direction when it advances from grain to grain. Grain deformation at regions away from the holes is not evident. However, extensive elongation of grains indicating large plastic deformation is evident at regions adjacent to the holes. The grain elongation is maximum at the regions of propagating of crack surfaces (Fig. 13). Due to these large elongation of the grains, compatibility between adjacent grains are lost at grain boundary regions resulting in the formation of sharp defects/cracks at these regions. Submicroscopic cracks were found nucleating at grains boundary regions only (a few isolated voids were observed inside the grains). The voids at regions of grain boundaries are large in number (Fig. 14). The main crack propagated through regions of high void population leading to a zigzag pattern when observed at a microscopic level. Voids nucleated ahead of the growing crack coalesce before they joined the main crack (Fig. 15 and Fig. 16). Stress intensity factor near the crack tip plays an important role for void growth and coalescences. This coalescence of the sharp micro-cracks ahead of the main crack leads to very high stress concentration facilitating the fracture process. In some cases, instead of single crack propagation, two or more cracks may be formed simultaneously and later they joined with each other by joining intermediate voids as shown in Fig. 17.

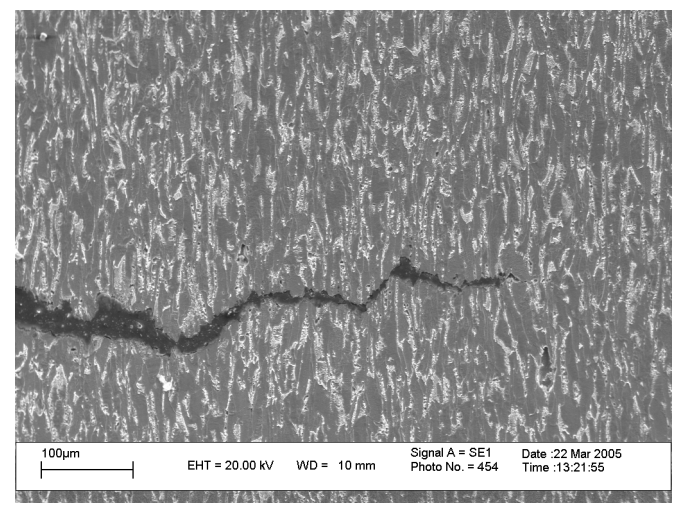

Figure 12: Fracture path under Microscope.

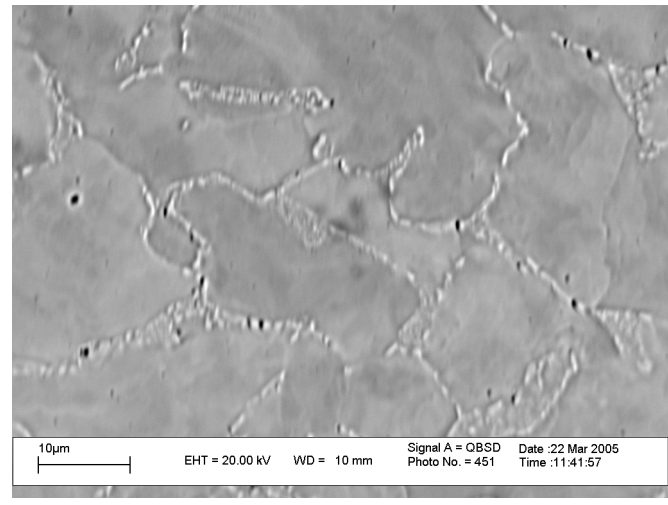

Figure 14: Voids present at grain boundary.

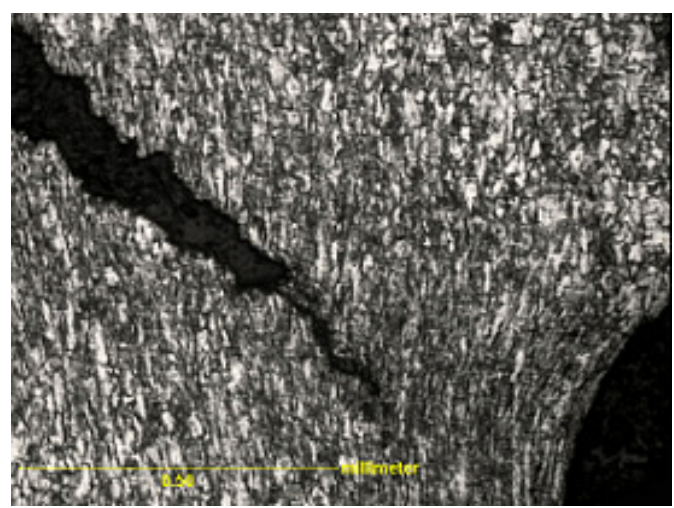

Figure 13: Grain in front of crack tip.

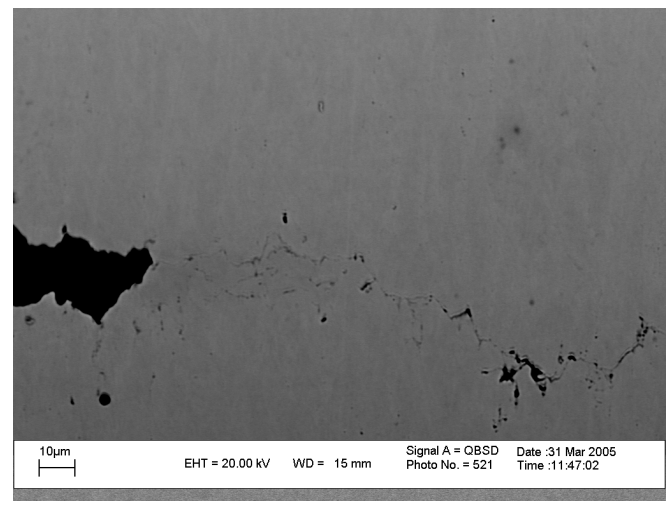

Figure 15: Void coalescence in front of crack. 


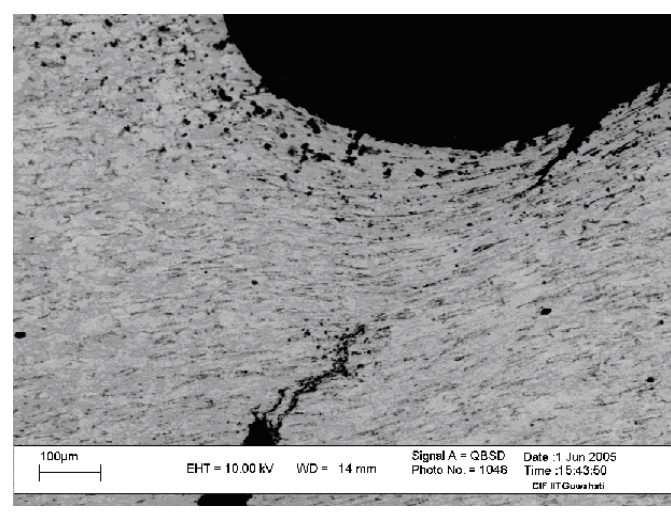

Figure 16: Void coalescence in front of crack.

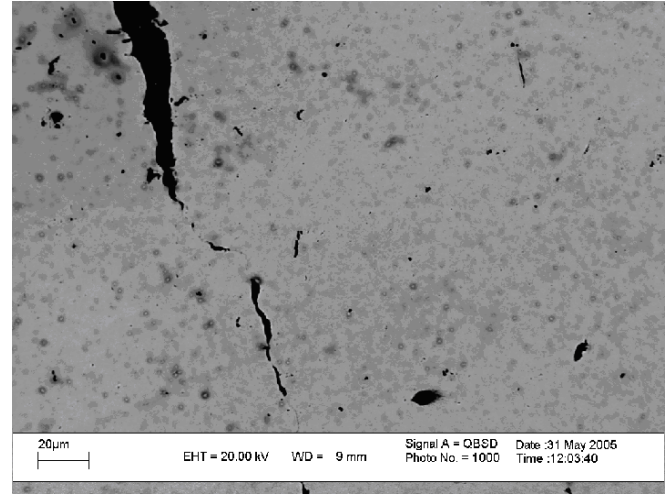

Figure 17: Multi-crack formation.

For specimen with smaller holes (of size $0.5 \mathrm{~mm}$ ), slip phenomena are observed as shown in Fig. 18. In this case, during slipping, load increases slightly and then decreases when fracture starts. As a very close approximation, the slip or glide can be considered analogous to the distortion produced in the pile of cards when it pushed from one end. Slip phenomena occur due to micro voids and dislocation movement in the materials. That slip phenomena promote for crack formation and propagation, which may be considered as Mode-II fracture.

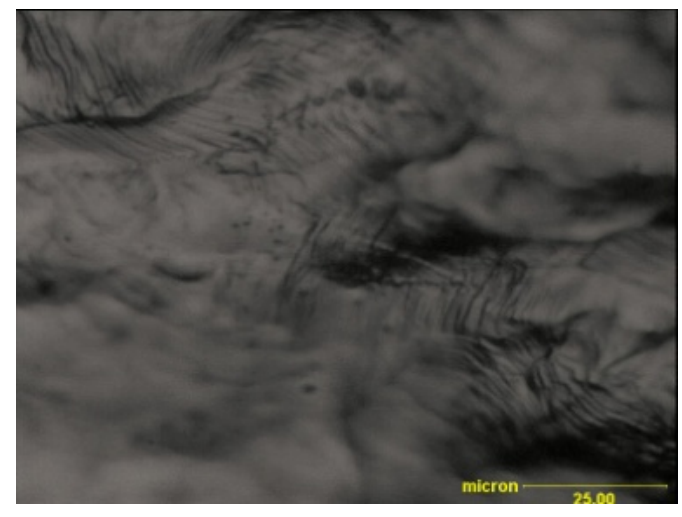

(a) Slip plane area near the bottom most hole

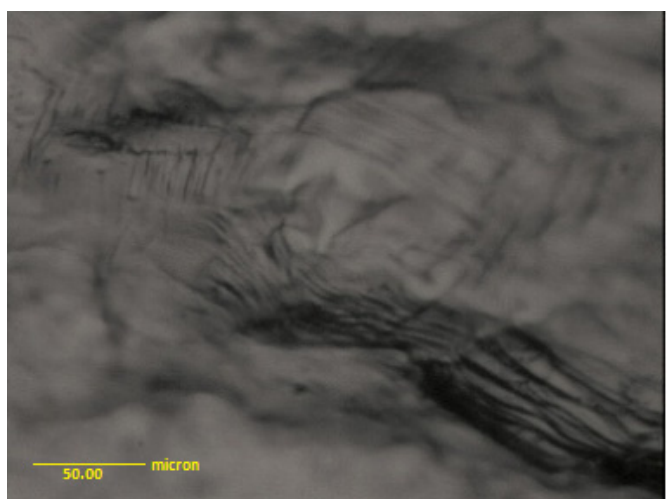

(b) Crack tends to form by slip plane

Figure 18: Slipping Phenomena in the specimen with $0.5 \mathrm{~mm}$ hole.

\section{CONCLUSIONS}

1 he following conclusions are drawn from the present experimental study:

I. If a material is initially unloaded beyond yield point, then in reloading its Young's Modulus value decreases but the elastic limit increases.

II. During tensile deformation beyond UTS two or more cracks may be created independently by coalescence of micro void instead of single crack growth.

III. Though the grain boundaries of the material are brittle, the grains are ductile in nature.

IV. During the progress of crack, the crack path is not truly linear, it moves in a zigzag path by joining the voids present just in front of the crack front.

V. The mechanical properties of specimen with holes decreases, compared to specimen without any hole.

VI. By increasing the angle of orientation to the tensile axis, the YP, UTS, E and fracture strain increase upto $45^{\circ}$ and then decreases. It indicates that with same amount of voids, present in different positions, the mechanical properties of the material are altered.

VII. The specimen with square array holes at $0^{\circ}\left(\right.$ or $\left.90^{\circ}\right)$ to the tensile axis exhibits least mechanical properties. Shear band is not found in this case.

VIII. No yield point phenomenon is observed in specimen with holes. 


\section{REFERENCES}

[1] A. Griffith, In: Proceeding of first international conference of applied mechanics, Delft (1924).

[2] E. Orowan, Report on Progress in physics, XII (1948) 185.

[3] S. H. Goods, L. M. Brown, Acta Metallurgica, 271 (978) 1.

[4] J. R. Rice, D. M. Tracey, J. of Applied Mechanics, 35 (1968) 379.

[5] J. P. Bandstra, D. A. Koss, Material Science and Engineering A, (2004) 399.

[6] R. Taktak, N. Benseddiq, A. Imad, Fatigue \& Fracture of Engineering Materials \& Structures, 32 (6) (2009) 525.

[7] P. F. Thomason, J. of Institute of Metals, 96 (1968) 360.

[8] F. U. Rui, D. Feng, X. Chen, J. of Iron and Steel Research, 14(5-1) (2007) 53.

[9] Tvergaard, Int. J. of Fracture, 148 (2007) 1.

[10] Gao, K. Jinkook, J. of solids and structures, 43(20) (2006), 6277.

[11] Z. L. Zhang, B. Skallerud, Int. J. of Damage Mechanics, 19(2) (2010) 153.

[12] M. S. Milza, D. C. Barton, P. Church, J. L. Sturges, J. Phys IV France (1997) 7.

[13] A. Osman, Engineering Failure Analysis, 13 (2006) 1260.

[14] S. K. Nath, U. K. Das, J. of Naval Architecture and Marine Engineering, (2006) 15.

[15] M. F. Ashby, R. A. Verrall, Acta metall., 21 (1973) 149.

[16] M. Stec, J. Faleskog, Int. J. of Fracture, 160 (2009) 151. 